\title{
Dietary $P_{i}$ deprivation in rats affects liver cAMP, glycogen, key steps of gluconeogenesis and glucose production
}

\author{
Wensheng XIE*, T. Luong TRAN†, Diane T. FINEGOOD† and Gérald VAN DE WERVE ${ }^{\star 1}$ \\ *Departments of Nutrition and Biochemistry, Centre de Recherche du CHUM, University of Montreal, Montreal, QC, Canada H3C 3J7, and $†$ School of Kinesiology, \\ Simon Fraser University, 8888 University Drive, Burnaby, BC, Canada V5A 1S6
}

We previously reported [Xie, Li, Méchin and van de Werve (1999) Biochem. J. 343, 393-396] that dietary phosphate deprivation for 2 days up-regulated both the catalytic subunit and the putative glucose-6-phosphate translocase of the rat liver microsomal glucose-6-phosphatase system, suggesting that increased hepatic glucose production might be responsible for the frequent clinical association of hypophosphataemia and glucose intolerance. We now show that liver cAMP was increased in rats fed with a diet deficient in $\mathrm{P}_{\mathrm{i}}$ compared with rats fed with a control diet. Accordingly, in the $\mathrm{P}_{\mathrm{i}}$-deficient group pyruvate kinase was inactivated, the concentration of phosphoenolpyruvate was increased and fructose 2,6-bisphosphate concentration was decreased. Phosphoenolpyruvate carboxykinase activity was marginally increased and glucokinase activity was unchanged by $\mathrm{P}_{\mathrm{i}}$ deprivation. The liver glycogen concentration decreased in the $\mathrm{P}_{\mathrm{i}}$-deficient group. In the fed state, plasma glucose concentration was increased and plasma $P_{i}$ and insulin concentrations were substantially decreased in the $\mathrm{P}_{\mathrm{i}}$-deficient group. All of these changes, except decreased plasma $P_{i}$, were cancelled in the overnight fasted $\mathrm{P}_{\mathrm{i}}$-deficient group. In the fasted $\mathrm{P}_{\mathrm{i}}$-deficient group, immediately after a glucose bolus, the plasma glucose level was elevated and the inhibition of endogenous glucose production was decreased. However, this mild glucose intolerance was not sufficient to affect the rate of fall of the glucose level after the glucose bolus. Taken together, these changes are compatible with a stimulation of liver gluconeogenesis and glycogenolysis by the $\mathrm{P}_{\mathrm{i}}$-deficient diet and further indicate that the liver might contribute to impaired glucose homeostasis in $\mathrm{P}_{\mathrm{i}}$-deficient states.

Key words: phosphate deficiency, endogenous glucose production, intravenous glucose tolerance, rat liver.

\section{INTRODUCTION}

Liver glucose production stems from glycogenolysis and gluconeogenesis to glucose 6-phosphate (G6P) and its subsequent hydrolysis by the glucose-6-phosphatase (G6Pase) complex in the endoplasmic reticulum membrane [1]. G6Pase comprises at least two proteins, a $36 \mathrm{kDa}$ catalytic subunit (p36) [2] and a $46 \mathrm{kDa}$ putative G6P translocase (p46) [3]. It has been reported that the overexpression of $\mathrm{p} 36$ in rat liver is sufficient to perturb glucose and lipid homeostasis in whole animals [4]. We have recently shown that a $\mathrm{P}_{\mathrm{i}}$-deficient $\left(-\mathrm{P}_{\mathrm{i}}\right)$ diet up-regulates rat liver microsomal G6Pase activity by the increased expression of both the p36 and p46 genes and the protein abundance of p36 only [5]. This finding suggests that the overproduction of glucose by the liver might contribute to glucose intolerance and insulin resistance, which have been documented in several diseases (hypophosphataemia rickets, adult-onset hypophosphataemia osteomalacia and renal $\mathrm{P}_{\mathrm{i}}$ leak) characterized with hypophosphataemia [6]. It was indeed reported that changes in plasma phosphate levels influenced sensitivity to insulin [7] and that gluconeogenesis was stimulated in cultured proximal tubular cells from kidney and in osteoblasts from mice with $\mathrm{X}$-linked hypophosphataemia $[8,9]$. A $\mathrm{P}_{\mathrm{i}}$-deficient diet could result in hypophosphataemia [10], which mimics the genetic hypophosphataemia, such as X-linked hypophosphataemia, even though several differences exist between these two $\mathrm{P}_{\mathrm{i}}$-deficient states [11].
It has also been reported that glucose-stimulated insulin secretion was lower in pancreatic islets from rats fed with a $\mathrm{P}_{\mathrm{i}}$-depleted diet [12]. Except for these results, it is uncertain how hypophosphataemia affects glucose metabolism in vivo; the liver glucose metabolism profile in the $\mathrm{P}_{\mathrm{i}}$-deficient state is unknown. In the present study we investigated the cause(s) for the up-regulation of G6Pase by the $\left(-\mathrm{P}_{\mathrm{i}}\right)$ diet and found that in the $\left(-\mathrm{P}_{\mathrm{i}}\right)$ group, liver cAMP, which enhances G6Pase gene expression [13,14], was increased compared with the control $\left(+\mathrm{P}_{\mathrm{i}}\right)$ group. In parallel, gluconeogenic key steps were stimulated and glycogen was decreased, the plasma glucose concentration was increased and the plasma insulin concentration was decreased. All these changes, except the lower plasma $\mathrm{P}_{\mathrm{i}}$ concentration, were cancelled by fasting overnight. However, endogenous glucose production was still less suppressed in the fasted $\left(-\mathrm{P}_{\mathrm{i}}\right)$ group, resulting in higher plasma glucose levels immediately after a glucose load.

\section{EXPERIMENTAL}

\section{Materials}

Glucose, triethanolamine, ATP, ADP, imidazole, GSH, fructose 6-phosphate disodium salt, sodium pyrophosphate, fructose 2,6bisphosphate $\left(\mathrm{F} 2,6 \mathrm{P}_{2}\right)$ tetrasodium salt, IDP, G6P, amylo-1,41,6-glucosidase, $\mathrm{PP}_{\mathrm{i}}$-phosphotransferase and glucose oxidase

Abbreviations used: G6P, glucose 6-phosphate; F2,6P , fructose 2,6-bisphosphate; GK, glucokinase; G6Pase, glucose-6-phosphatase; IVGTT, intravenous glucose tolerance test; PEP, phosphoenolpyruvate; PEPCK, phosphoenolpyruvate carboxykinase; PK, pyruvate kinase; PKA, cAMPdependent protein kinase.

To whom correspondence should be addressed (e-mail gerald-van-de-werve@hotmail.com). 
were from Sigma (St Louis, MO, U.S.A.). NADP, NADH, phosphoenolpyruvate (PEP), pyruvate kinase (PK), malate dehydrogenase, lactate dehydrogenase, hexokinase, G6P dehydrogenase, aldolase, glyceraldehyde-3-phosphate dehydrogenase and triose-3-phosphate isomerase were purchased from Boehringer (Laval, Québec, Canada). $\left[{ }^{3} \mathrm{H}\right] \mathrm{cAMP}$ was from NEN (Boston, MA, U.S.A.). $\left[3-{ }^{3} \mathrm{H}\right]$ Glucose was purchased from Mandel Scientific Company (Guelph, Ontario, Canada). A cAMP assay kit was purchased from Amersham (Baie d'Urfé, Québec, Canada). Rat insulin ELISA kit was from Crystal Chem (Chicago, IL, U.S.A.).

\section{Animals}

Male Sprague-Dawley rats (approx. $300 \mathrm{~g}$ body weight) were used for all experiments. Rats used for liver sampling were fed for $48 \mathrm{~h}$ with either a $\mathrm{P}_{\mathrm{i}}$-deficient diet (no. 86128) $\left(-\mathrm{P}_{\mathrm{i}}\right)$ or a control diet (no. 86129) $\left(+\mathrm{P}_{\mathrm{i}}\right)$ (Teklad, Madison, WI, U.S.A.) containing $0.03 \%$ or $1 \%(\mathrm{w} / \mathrm{w})$ phosphate respectively. All other components were the same in both diets. Food was removed from the cages of the fasted group overnight before they were killed. Five rats were used for all the groups except for the fasted $\left(-\mathrm{P}_{\mathrm{i}}\right)$ group, which contained six rats. For sampling of the livers, rats were decapitated on the morning of the third day. For rats undergoing an intravenous glucose tolerance test (IVGTT), catheters were inserted as described [15]. In brief, the animal was anaesthetized and sterile catheters were placed in the left carotid artery (for blood sampling) and the right jugular vein (for tracer infusion and bolus injection). After 1 week of recovery, the rats were fed with $\left(-\mathrm{P}_{\mathrm{i}}\right)$ or $\left(+\mathrm{P}_{\mathrm{i}}\right)$ diet for $48 \mathrm{~h}$, then fasted overnight before the IVGTT was performed. Four rats were used in the $\left(-\mathrm{P}_{\mathrm{i}}\right)$ group and five in the $\left(+\mathrm{P}_{\mathrm{i}}\right)$ group. In a separate group of animals fed with the $\left(-\mathrm{P}_{\mathrm{i}}\right)$ or $\left(+\mathrm{P}_{\mathrm{i}}\right)$ diet for $48 \mathrm{~h}(n=5$ for each diet), blood samples were taken at 09:00h on the morning of the third day for the measurement of fed-state plasma glucose and insulin.

\section{IVGTT}

The IVGTT was performed as described [15]. At 10 min after the first blood sample (regarded as time point $0 \mathrm{~min}$ ), a primed, continuous infusion of $\left[3-{ }^{3} \mathrm{H}\right]$ glucose was started. The priming dose $(9 \mu \mathrm{Ci} / \mathrm{ml})$ was given within $60 \mathrm{~s}$ and the continuous infusion $(10 \mu \mathrm{Ci} / \mathrm{ml})$ was infused at $0.015 \mathrm{ml} / \mathrm{min}(0.15 \mu \mathrm{Ci} / \mathrm{min})$. Blood samples were taken at 120, 130, 140, 150 and $155 \mathrm{~min}$. At $160 \mathrm{~min}$ a glucose bolus $(0.3 \mathrm{~g} / \mathrm{kg}$ body weight $)$ mixed with tracer glucose $(13 \mu \mathrm{Ci})$ was given within $1 \mathrm{~min}$. Blood samples were taken at 162, 165, 170, 175, 180, 190, 220 and $250 \mathrm{~min}$. Haematocrit was measured before and after the experiment. Blood sample handling and determinations of plasma glucose and plasma specific radioactivity were performed as described [15]. Plasma insulin was assayed with a rat insulin ELISA kit.

\section{Liver treatment}

Livers were homogenized in $50 \mathrm{mM}$ Hepes/Tris $(\mathrm{pH} 7.3) / 250 \mathrm{mM}$ sucrose and further processed at $4{ }^{\circ} \mathrm{C}$. The homogenates were centrifuged at $1000 \mathrm{~g}$ for $10 \mathrm{~min}$; the first supernatant was recovered and further centrifuged at $12000 \boldsymbol{g}$ for $10 \mathrm{~min}$. The second supernatant was centrifuged at $100000 \mathrm{~g}$ for $60 \mathrm{~min}$. This last high-speed supernatant was used for the assay of glucokinase (GK), PK and phosphoenolpyruvate carboxykinase (PEPCK). Before homogenization, part of the liver from each rat was freeze-clamped in liquid nitrogen and kept at $-80{ }^{\circ} \mathrm{C}$ pending other assays.

\section{Liver CAMP}

Approx. $100 \mathrm{mg}$ of frozen liver was homogenized in $1 \mathrm{ml}$ of cold $6 \%(\mathrm{w} / \mathrm{v})$ trichloroacetic acid containing a trace amount of $\left[{ }^{3} \mathrm{H}\right] \mathrm{cAMP}$ as internal control. Denatured proteins were removed by centrifugation and the trichloroacetic acid was extracted from the supernatant four times with 5 vol. of water-saturated ether. cAMP was assayed in the aqueous phase in accordance with the instructions of the assay kit. Recovery was calculated from the carry-over of $\left[{ }^{3} \mathrm{H}\right] \mathrm{cAMP}$ in the assay samples.

\section{Enzyme assays}

GK activity was assayed as described previously [16]. PK and PEPCK activities were measured at room temperature as detailed previously $[17,18]$. The active form of PK was measured in the presence of $0.15 \mathrm{mM}$ PEP and the total activity at $5.0 \mathrm{mM}$ PEP [17]. One unit of enzyme is defined as the amount of enzyme converting $1 \mu \mathrm{mol}$ of substrate/min under the assay conditions.

\section{Metabolite assays}

Pyruvate, $\mathrm{P}_{\mathrm{i}}$ and PEP were measured in neutralized trichloroacetic acid extracts by classical procedures [19]. Glycogen [19] and $\mathrm{F} 2,6 \mathrm{P}_{2}[20]$ were measured in neutralized $\mathrm{NaOH}$ extracts.

\section{Data analysis}

The rate of glucose disappearance during IVGTT $\left(K_{\mathrm{g}}\right)$ was calculated as the slope of the natural logarithm of plasma glucose against time between the 162 and $180 \mathrm{~min}$ time points, as described in [15]. Endogenous glucose production was calculated as described in [21]. Statistical analysis was performed according to Student's $t$ test. Differences were considered significant at $P<0.05$.

\section{RESULTS AND DISCUSSION}

Our previous report demonstrated that a $\left(-\mathrm{P}_{\mathrm{i}}\right)$ diet up-regulates liver G6Pase activity [5]. To verify whether hepatic glucose production might be enhanced in this condition, we measured plasma $\mathrm{P}_{\mathrm{i}}$, insulin and glucose concentrations, insulin secretion, glucose disposal and endogenous glucose appearance after an IVGTT, and also liver glycogen and key regulatory steps of gluconeogenesis. These steps are at the PEP/pyruvate, fructose 6-phosphate/fructose 1,6-bisphosphate and glucose/G6P cycles [22]. Feeding rats for 2 days with a $\left(-P_{i}\right)$ diet, with (fasted) or without (fed) an overnight fast, decreased the plasma phosphate

Table 1 Effect of a $\mathbf{P}_{\mathrm{i}}$-deficient diet on plasma and liver parameters in the fed state

Assays were performed as described in the Experimental section. Samples were from rats fed with a control or P-deficient diet for $48 \mathrm{~h}$ in the fed state. The PK activity ratio is the ratio of the activities measured at 0.15 and $5 \mathrm{mM}$ PEP respectively. Results are means \pm S.E.M. for each group $(n=5)$. ${ }^{*} P<0.05$ (unpaired Student's $t$ test); n.s., not significantly different.

\begin{tabular}{|c|c|c|c|}
\hline Parameter & Group .. & $\left(+P_{i}\right)$ & $\left(-P_{i}\right)$ \\
\hline Plasma $\mathrm{P}_{\mathrm{i}}(\mu \mathrm{M})$ & & $1.5 \pm 0.25$ & $0.63 \pm 0.19^{*}$ \\
\hline Liver $\mathrm{P}_{\mathrm{i}}(\mu \mathrm{M})$ & & $3.83 \pm 0.10$ & $4.35 \pm 0.32$ (n.s.) \\
\hline Liver cAMP (nmol/g of liver) & & $1.6 \pm 0.13$ & $2.2 \pm 0.09^{*}$ \\
\hline Liver PK activity ratio & & $0.241 \pm 0.044$ & $0.134 \pm 0.046^{*}$ \\
\hline Liver PEP (nmol/g of liver) & & $30 \pm 3.2$ & $48 \pm 3.0^{*}$ \\
\hline Liver $\mathrm{F} 2,6 \mathrm{P}_{2}(\mathrm{nmol} / \mathrm{g}$ of liver) & & $7.5 \pm 0.32$ & $3.5 \pm 0.42^{\star}$ \\
\hline Liver glycogen (mg/g of liver) & & $17.6 \pm 1.24$ & $10 \pm 0.93^{*}$ \\
\hline Plasma glucose concentration (mM) & & $6.8 \pm 0.3$ & $9.2 \pm 0.5^{\star}$ \\
\hline Plasma insulin concentration (pM) & & $251+17$ & $111+5.9^{*}$ \\
\hline
\end{tabular}


Table 2 Effect of a $\mathbf{P}_{\mathrm{i}}$-deficient diet on plasma and liver parameters in the fasted state

Assays were performed as described in the Experimental section. Samples were from rats fed with a control or $\mathrm{P}_{\mathrm{i}}$-deficient diet for $48 \mathrm{~h}$ before being fasted overnight. The PK activity ratio is the ratio of the activities measured at 0.15 and $5 \mathrm{mM}$ PEP respectively. $K_{\mathrm{g}}$, the glucose disapperance rate during the IVGTT, was calculated as described in the Data analysis section. Results are means \pm S.E.M. for each group $(n=4-6)$. ${ }^{*} P<0.05$ (unpaired Student's $t$ test); n.S., not significantly different.

\begin{tabular}{|c|c|c|c|}
\hline Parameter & Group... & $\left(+P_{i}\right)$ & $\left(-P_{i}\right)$ \\
\hline Plasma $\mathrm{P}_{\mathrm{i}}(\mu \mathrm{M})$ & & $1.82 \pm 0.12$ & $0.75 \pm 0.08^{*}$ \\
\hline Liver $\mathrm{P}_{\mathrm{i}}(\mu \mathrm{M})$ & & $7.51 \pm 0.39$ & $6.43 \pm 0.52$ (n.s.) \\
\hline Liver cAMP ( $\mathrm{nmol} / \mathrm{g}$ of liver) & & $2.02 \pm 0.25$ & $2.10 \pm 0.21$ (n.s.) \\
\hline Liver PK activity ratio & & $0.060 \pm 0.008$ & $0.065 \pm 0.011$ (n.s.) \\
\hline Liver PEP (nmol/g of liver) & & $56 \pm 6.6$ & $51 \pm 1.42$ (n.s.) \\
\hline Liver $\mathrm{F}_{2,6 \mathrm{P}_{2}}$ (nmol/g of liver) & & $3.15 \pm 0.39$ & $2.86 \pm 0.38$ (n.s.) \\
\hline Liver glycogen (mg/g of liver) & & $2.45 \pm 0.48$ & $2.41 \pm 0.41$ (n.s.) \\
\hline Plasma glucose concentration (mM) & & $5.07 \pm 0.34$ & $5.56 \pm 0.52$ (n.s.) \\
\hline Plasma insulin concentration (pM) & & $72.1 \pm 9.3$ & $66.4 \pm 6.7$ (n.s.) \\
\hline$K_{\mathrm{g}}(\% / \min )$ & & $1.9 \pm 0.4$ & $2.2 \pm 0.6$ (n.s.) \\
\hline
\end{tabular}

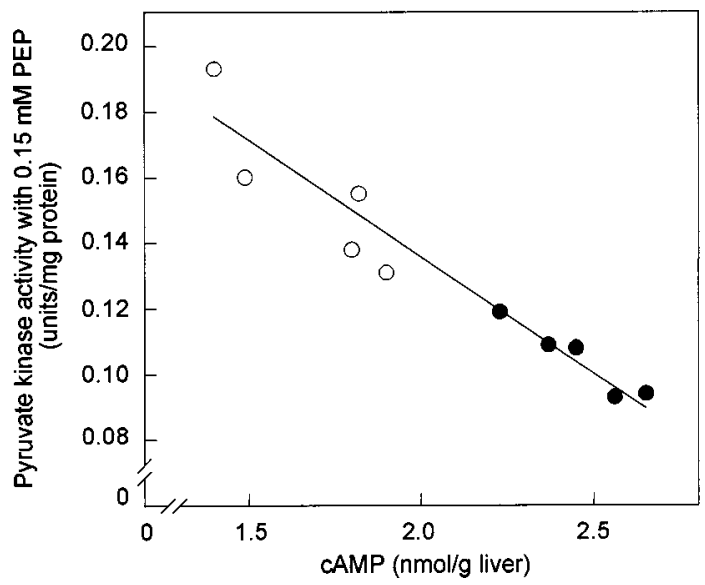

Figure 1 Correlation between cAMP concentration and PK activity

Individual values of liver CAMP concentration and the active form of PK, measured as described in the Experimental section, were plotted against each other. Symbols: $O,\left(+P_{i}\right)$ group; $\left(-P_{i}\right)$ group.

concentration by half, but liver $\mathrm{P}_{\mathrm{i}}$ was the same in all groups (compare Tables 1 and 2). This was accompanied by a decrease in insulin concentration and an increase in plasma glucose concentration, and an increase in liver cAMP, but only in the fed $\left(-\mathrm{P}_{\mathrm{i}}\right)$ group (Table 1). In the fasted group, liver cAMP was not affected by the diet; neither was plasma insulin nor glucose. These results suggest that the cause for increased cAMP in the fed $\left(-\mathrm{P}_{\mathrm{i}}\right)$ group was the lower plasma insulin and the consequence was hyperglycaemia. Accordingly, in the fasted $\left(-\mathrm{P}_{\mathrm{i}}\right)$ group, the absence of an increase in cAMP level is consistent with unchanged plasma insulin and glucose levels. Plasma glucagon concentrations could not be measured in this work, owing to the limited size of blood samples; however, the changes in cAMP are consistent with the changes in insulin concentrations, suggesting that the insulin-to-glucagon ratio changed in parallel.

\section{PEP/pyruvate cycle}

The PK activity ratio was found to be lower in the $\left(-\mathrm{P}_{\mathrm{i}}\right)$ group in the fed state (Table 1), while the total PK activity, measured at $5.0 \mathrm{mM}$ PEP, was unchanged by $\mathrm{P}_{\mathrm{i}}$ deprivation $(0.766 \pm 0.024$ compared with $0.734 \pm 0.043$ unit/mg of protein). Figure 1 shows that, in fed animals, there was a linear inverse correlation between the active form of PK and cAMP and that all individual values of cAMP and PK were different between the two groups. These results suggest that the inactivation of PK in the fed $\left(-\mathrm{P}_{\mathrm{i}}\right)$ group is the consequence of the increased liver cAMP level and presumed activation of cAMP-dependent protein kinase (PKA). PKA has indeed been well documented to phosphorylate and inactivate $\mathrm{PK}$ in vitro [23], an effect mediated by glucagon in the perfused liver [24] and in isolated hepatocytes [17]. In the latter [17], the dose-dependent stimulation of gluconeogenesis by glucagon was paralleled by the inactivation of PK. The fact that the total PK activity was unaffected by the $\left(-\mathrm{P}_{\mathrm{i}}\right)$ diet implies that the effect on PK activity was an acute regulation, rather than a long-term effect. The stimulation of gluconeogenesis by the inactivation of $\mathrm{PK}$ is mediated by PEP, which accumulates and, by mass action, pushes the intermediate towards glucose. Accordingly, liver PEP concentrations were increased in the $\left(-\mathrm{P}_{\mathrm{i}}\right)$ group (Table 1). Liver PEPCK activity also tended to be higher in the $\left(-\mathrm{P}_{\mathrm{i}}\right)$ group $(16.56 \pm 1.04$ compared with $18.44 \pm 1.38$ m-units/mg of protein), but the difference was not statistically significant. The higher PEP concentration is therefore more likely to have been the result of its diminished conversion into pyruvate by PK rather than its increased production by PEPCK. These results together show that liver cAMP content, PK activity and PEP content were all altered in the fed state by the $\left(-\mathrm{P}_{\mathrm{i}}\right)$ diet. However, these changes were not observed in the fasted state, even though the plasma $\mathrm{P}_{\mathrm{i}}$ concentration was still significantly lower in the fasted $\left(-\mathrm{P}_{\mathrm{i}}\right)$ group, as shown in Table 2 . It therefore seems that fasting might compensate for the effect of $\mathrm{P}_{\mathrm{i}}$ deficiency on these parameters.

\section{Fructose 6-phosphate/fructose 1,6-bisphosphate cycle}

Another key reaction in gluconeogenesis is catalysed by fructose1,6-bisphosphatase and is inhibited by $\mathrm{F} 2,6 \mathrm{P}_{2}[25,26]$. The concentration of $\mathrm{F} 2,6 \mathrm{P}_{2}$ is determined by the activity of the bifunctional enzyme 6-phosphofructo-2-kinase/fructose-2,6bisphosphatase. The kinase activity of this enzyme is inactivated and the phosphatase activity is activated by PKA in liver [27,28]. An increase in cAMP level such as that observed here in the liver of rats fed with a $\left(-\mathrm{P}_{\mathrm{i}}\right)$ diet should therefore decrease $\mathrm{F} 2,6 \mathrm{P}_{2}$ level, by a concerted inhibition of its synthesis and a stimulation of its degradation. Table 1 shows that this is indeed true, because $\mathrm{F} 2,6 \mathrm{P}_{2}$ concentrations were decreased by half in the fed $\left(-\mathrm{P}_{\mathrm{i}}\right)$ group. The resulting de-inhibition of fructose-1,6bisphosphatase would be in agreement with a stimulation of gluconeogenesis. The fact that $\mathrm{F} 2,6 \mathrm{P}_{2}$ concentration decreased in the $\left(-\mathrm{P}_{\mathrm{i}}\right)$ group suggests that this metabolite does not have a role in the overexpression of G6Pase found in this condition [5], because $\mathrm{F} 2,6 \mathrm{P}_{2}$ is a known stimulator of $\mathrm{p} 36$ gene expression [29]. Similarly to the changes of CAMP, PK and PEP in the fasted state, $\mathrm{F} 2,6 \mathrm{P}_{2}$ concentrations were not significantly different in the fasted state as shown in Table 2.

\section{Glucose/G6P cycle}

The up-regulation of G6Pase activity by the $\left(-\mathrm{P}_{\mathrm{i}}\right)$ diet [5] would favour net liver glucose production only if the opposing reaction 


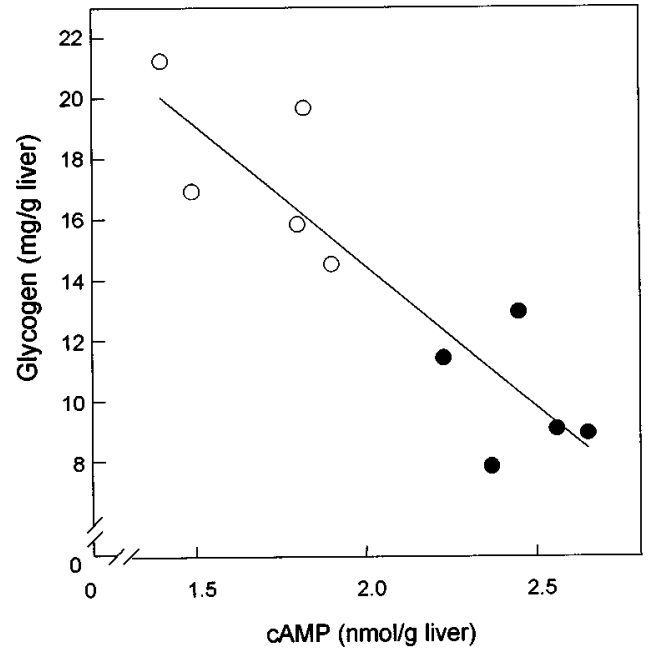

Figure 2 Correlation between cAMP and glycogen concentrations

Individual values of liver CAMP and glycogen concentrations, measured as described in the Experimental section, were plotted against each other. Symbols: $O,\left(+P_{i}\right)$ group; $\mathbf{O}\left(-P_{\mathrm{i}}\right)$ group.

catalysed by GK were unchanged or decreased. Experiments showed that, in comparison with the $\left(+\mathrm{P}_{\mathrm{i}}\right)$ group, GK activity was not modified in the $\left(-P_{i}\right)$ group $(7.74 \pm 1.53$ compared with $8.1 \pm 0.94 \mathrm{~m}$-units $/ \mathrm{mg}$ of protein in the fed state), thus indicating that enhanced G6Pase activity alone might be responsible, at this ultimate cycle, for increased glucose production in the liver. Given that the mRNA abundance of both the putative G6P transporter [5] and the catalytic subunit [5,13] of G6Pase are stimulated by cAMP, it is probable that the higher cAMP level in the liver of the animals fed with a low- $\mathrm{P}_{i}$ diet was the cause of increased gene expression of the components of G6Pase and increased activity of this enzyme [5]. However, it cannot be the cause of up-regulation of G6Pase in the fasted $\left(-\mathrm{P}_{\mathrm{i}}\right)$ group, in which liver cAMP concentration was unchanged compared with the fasted $\left(+\mathrm{P}_{\mathrm{i}}\right)$ group. Therefore another mechanism, related to the decrease in plasma $P_{i}$ concentration, must be responsible for increased G6Pase activity in the fasted $\left(-\mathrm{P}_{\mathrm{i}}\right)$ group [5].

\section{Glycogen}

To determine whether the increase in cAMP observed in the livers of the $\left(-\mathrm{P}_{\mathrm{i}}\right)$ group had also affected glycogen degradation, which is stimulated by cAMP, we measured the liver glycogen content, which was markedly decreased in the $\left(-\mathrm{P}_{\mathrm{i}}\right)$ group in the fed state (Table 1). Figure 2 shows that there was a linear inverse correlation between cAMP and glycogen concentrations in the two groups of rats and that all individual values of cAMP and glycogen were different between the two groups. It seems that the glycogen concentration was decreased almost by half in the livers of rats fed with a low- $\mathrm{P}_{\mathrm{i}}$ diet and that this decrease was associated with the increase in cAMP concentration, suggesting a cAMPinduced glycogenolysis in this group. In the fasted state, the glycogen content of both groups decreased to very low levels. This result, combined with those of cAMP, PK and PEP in the fasted state, indicates that the proper effect of $P_{i}$ deficiency was therefore probably blunted in the fasted group.

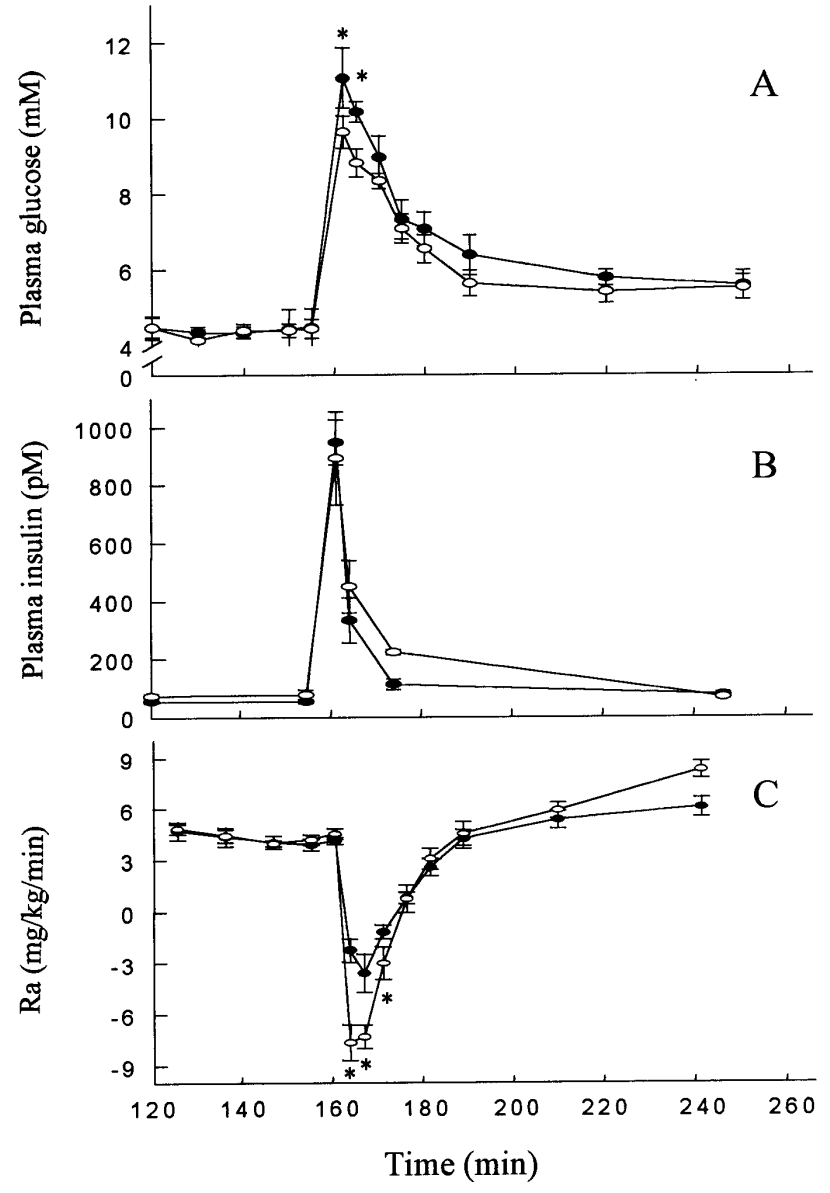

Figure 3 Plasma glucose and insulin levels and endogenous glucose production during IVGTT

The IVGTT was performed with rats fasted overnight as described in the Experimental section. $\left[3-{ }^{3} \mathrm{H}\right] \mathrm{Glucose}$ infusion started at time $0 \mathrm{~min}$; the glucose bolus mixed with tracer $\left[3-{ }^{3} \mathrm{H}\right]$ glucose was injected at $160 \mathrm{~min}$. Results are means \pm S.E.M. for $n=4$ or 5 . Symbols: $O,\left(+P_{i}\right)$ group; - $\left(-\mathrm{P}_{\mathrm{i}}\right.$ ) group. ${ }^{\star} P<0.05$ (unpaired Student's $t$ test). (A) Plasma glucose concentration was measured at each time point during IVGTT. (B) Plasma insulin concentration was measured at time points $120,155,162,165,175$ and $250 \mathrm{~min}$. (C) The endogenous glucose production parameter, $R a$, was calculated from the plasma tracer data and plasma glucose concentration as described in the Experimental section.

\section{Glucoregulatory effects}

The effects of the low- $\mathrm{P}_{\mathrm{i}}$ diet on regulatory steps of gluconeogenesis were manifested at the level of the whole animal as elevated plasma glucose levels during glucose loading. In the fed state, plasma glucose levels were increased in the $\left(-\mathrm{P}_{\mathrm{i}}\right)$ group (Table 1). After an intravenous glucose load during the IVGTT performed in rats fasted overnight, plasma glucose levels were higher in the $\left(-\mathrm{P}_{\mathrm{i}}\right)$ group as shown in Figure 3(A), even though the rates of glucose decrease $\left(K_{\mathrm{g}}\right)$ were similar (Table 2). These results suggest a mild state of glucose intolerance in the $\left(-\mathrm{P}_{\mathrm{i}}\right)$ group in the fasted state. This result is consistent with a previous observation [30] that showed a slight tendency to hyperglycaemia during an IVGTT in patients with X-linked hypophosphataemia. There was no difference, however, in the plasma glucose or insulin levels after an overnight fast (Table 2), in agreement with a potential compensating effect of fasting on $\mathrm{P}_{\mathrm{i}}$ deficiency. Although plasma insulin concentration was sub- 
stantially lower in the $\left(-\mathrm{P}_{\mathrm{i}}\right)$ group in the fed state (Table 1), the insulin response was not significantly different after the glucose bolus in the IVGTT, as shown in Figure 3(B). The fact that plasma glucose was only mildly increased and that the rate of decrease in glucose concentration was unaffected implies that $48 \mathrm{~h}$ of the $\mathrm{P}_{\mathrm{i}}$-deficient diet might still have been insufficient to cause marked glucose intolerance, but also that $\mathrm{P}_{\mathrm{i}}$ deficiency was partly compensated for by fasting. Endogenous glucose production was, however, significantly less suppressed in the fasted $\left(-\mathrm{P}_{\mathrm{i}}\right)$ group after a glucose bolus (Figure 3C), contributing to the hyperglycaemia. The decreased suppression of endogenous glucose production could have been due to the increased G6Pase activity because its change was still evident [5], whereas changes in other parameters were lessened by fasting (Table 2). All of these results are consistent with the marked decrease in plasma insulin and increase in glucose concentration in the fed $\left(-\mathrm{P}_{\mathrm{i}}\right)$ group. In the fasted state, when plasma insulin concentration had already been lowered by fasting and no significant effect resulted from the $\mathrm{P}_{\mathrm{i}}$-deficient diet on insulin concentration, the plasma glucose concentration was correspondingly not significantly different from that in the fasted $\left(-\mathrm{P}_{\mathrm{i}}\right)$ group.

\section{Conclusion}

Our previous work indicated that dietary $\mathrm{P}_{\mathrm{i}}$ deficiency enhanced liver G6Pase expression and activity [5]. The present observations show that the metabolic liver profile of rats fed with a $P_{i}$-deficient diet is that of enhanced endogenous glucose production resulting from stimulated gluconeogenesis and glycogenolysis. This increased glucose production is most probably triggered by an increase in cAMP concentration, as documented by the inactivated $\mathrm{PK}$, higher $\mathrm{PEP}$ and lower $\mathrm{F} 2,6 \mathrm{P}_{2}$ and glycogen concentrations in the fed state. Similarly, a high cAMP concentration can account for the increased expression of G6Pase and it might be that this long-term effect on G6Pase gene expression was still maintained in the fasted state while other acute effects were lessened by fasting, because these changes (lower plasma insulin, higher liver cAMP and lower glycogen concentrations, lower PK activity ratio, higher PEP and lower $\mathrm{F} 2,6 \mathrm{P}_{2}$ concentrations) are already induced by fasting itself. How $\mathrm{P}_{\mathrm{i}}$ deficiency affects the liver in vivo is unknown. Our results demonstrate that both groups of rats ingested the same amount of food $\left[40.5 \pm 6.68\right.$ for the $\left(+\mathrm{P}_{\mathrm{i}}\right)$ group compared with $41.4 \pm 7.75 \mathrm{~g}$ for the $\left(-\mathrm{P}_{\mathrm{i}}\right)$ group] during the period of feeding with the special diet, excluding the possibility of lower caloric intake in the $\left(-\mathrm{P}_{\mathrm{i}}\right)$ group. A decreased fed-state plasma insulin, assuming that the glucagon level is unchanged or increased, suggests that dietary $\mathrm{P}_{i}$ deficiency might decrease the insulin-toglucagon ratio entering the liver, which might in turn increase the formation of cAMP in the liver. With respect to insulin secretion, the effect of phosphate deficiency is not consistent. It has been reported that glucose-stimulated insulin secretion was lower in perfused pancreatic islets from rats fed with a $\mathrm{P}_{\mathrm{i}}$-depleted diet for 6 weeks [12]. In contrast, however, serum insulin levels were substantially higher in the genetic hypophosphataemic patients during an IVGTT [30]. This difference might be due to different experimental conditions or might result from the differences between the $\mathrm{P}_{\mathrm{i}}$-deficient diet animal model and the genetic hypophosphataemia [11]. Another intriguing possibility for impaired glucose metabolism in the $\mathrm{P}_{\mathrm{i}}$-deficienct state would be that one or more hormones associated with phosphate homeostasis, such as phosphatonin [31] or stanniocalcin [32], are regulated by dietary $\mathrm{P}_{\mathrm{i}}$ deprivation and affect liver cAMP. It has indeed been reported that the newly discovered stanniocalcin 2 was primarily expressed in human pancreatic $\alpha$-cells and could affect glucose metabolism [33].

We thank Dr Richard Béliveau and Dr Edith Beaulieu (UQAM) for providing the diets and animal care, Dr Marie-Claire Méchin for helpful discussion, Lily Huang for the animal surgery, and Guylaine Gévry for the artwork. This work was supported by Grant MT-10804 from the Medical Research Council of Canada (to G.v.d.W.) and by a grant from the Canadian Diabetes Association (to D.T.F.). An abstract of this work was presented at the President Poster Session in the 60th American Diabetes Association Conference [34]

\section{REFERENCES}

1 Foster, J. D. F., Pederson, B. A. and Nordlie, R. C. (1997) Glucose-6-phosphatase structure, regulation, and function: an update. Proc. Soc. Exp. Biol. Med. 215, 314-332

2 Lei, K. J., Shelly, L. L., Pan, C. J., Sidbury, J. B. and Chou, J. Y. (1993) Mutations in the glucose-6-phosphatase gene that cause glycogen storage disease type 1a. Science 262, 580-583

3 Gerin, I., Veiga-da-Cunha, M., Achouri, Y., Collet, J. F. and Van Schaftingen, E. (1997) Sequence of a putative glucose 6-phosphate translocase, mutated in glycogen storage disease type lb. FEBS Lett. 419, 235-238

4 Trinh, K. Y., O'Doherty, R. M., Anderson, P., Lange, A. J. and Newgard, C. B. (1998) Perturbation of fuel homeostasis caused by overexpression of the glucose-6phosphatase catalytic subunit in liver of normal rats. J. Biol. Chem. 273, 31615-31620

5 Xie, W. S., Li, Y. Z., Méchin, M.-C. and van de Werve, G. (1999) Up-regulation of liver glucose-6-phosphatase in rats fed with a $P_{i}$-deficient diet. Biochem. J. 343, 393-396

6 DeFronzo, R. A. and Lang, R. (1980) Hypophosphatemia and glucose intolerance: evidence for tissue insensitivity to insulin. N. Engl. J. Med. 303, 1259-1263

7 Nowicki, M., Fliser, D., Fode, P. and Ritz, E. (1996) Changes in plasma phosphate levels influence insulin sensitivity under euglycemic conditions. J. Clin. Endocrinol. Metab. 81, 156-159

8 Capparelli, A. W., Roh, D., Dhiman, J. K., Jo, O. D. and Yanagawa, N. (1992) Altered proximal tubule glucose metabolism in X-linked hypophosphatemia mice. Endocrinology 130, 328-334

9 Rifas, L., Gupta, A., Hruska, K. A. and Avioli, L. V. (1995) Altered osteoblast gluconeogenesis in X-linked hypophosphatemia mice is associated with a depressed intracellular pH. Calcif. Tissue Int. 57, 60-63

10 Jara, A., Lee, E., Stauber, D., Moatamed, F., Felsenfeld, A. J. and Kleeman, C. R. (1999) Phosphate depletion in the rat: effect of bisphosphonates and the calcemic response to PTH. Kidney Int. 55, 1434-1443

11 Econs, M. J. (1999) New insights into the pathogenesis of inherited phosphate wasting disorders. Bone 25, 131-135

12 Zhou, X. J., Fadda, G. Z., Perna, A. F. and Massry, S. G. (1991) Phosphate depletion impairs insulin secretion by pancreatic islets. Kidney Int. 39, 120-128

13 Lange, A. J., Argaud, D., El-Maghrabi, M. R., Pan, W., Maitra, S. R. and Pilkis, S. J. (1994) Isolation of a cDNA for the catalytic subunit of rat liver glucose-6phosphatase: regulation of gene expression in FAO hepatoma cells by insulin, dexamethasone and cAMP. Biochem. Biophys. Res. Commun. 201, 302-309

14 Li, Y. Z., Méchin, M.-C. and van de Werve, G. (1999) Diabetes affects similarly the catalytic subunit and putative glucose-6-phosphate translocase of glucose-6phosphatase. J. Biol. Chem. 274, 33866-33868

15 McArthur, M. D., You, D., Klapstein, K. and Finegood, D. (1999) Glucose effectiveness is the major determinant of intravenous glucose tolerance in the rat. Am. J. Physiol. 276, E739-E746

16 Bontemps, F., Hue, L. and Hers, H.-G. (1978) Phosphorylation of glucose in isolated rat hepatocytes. Sigmoidal kinetics explained by the activity of glucokinase alone. Biochem. J. 174, 603-611

17 Feliu, J. E., Hue, L. and Hers, H.-G. (1976) Hormonal control of pyruvate kinase activity and of gluconeogenesis in isolated hepatocytes. Proc. Natl. Acad. Sci. U.S.A. 73, 2762-2766

18 Chang, H. C. and Lane, M. D. (1966) The enzymatic carboxylation of phosphoenolpyruvate. II. Purification and properties of liver mitochondrial phosphoenolpyruvate carboxykinase. J. Biol. Chem. 241, 2413-2420

19 Czok, R. and Lamprecht, W. (1983) Pyruvate, phosphoenolpyruvate and D-glycerate-2phosphate. In Methods of Enzymatic Analysis (Bergmeyer, H. U., ed.), vol. 3, pp. 1447-1451, Verlag Chemie, Weinheim

20 Van Schaftingen, E., Lederer, B., Bartrons, R. and Hers, H. G. (1982) A kinetic study of pyrophosphate: fructose-6-phosphate phosphotransferase from potato tubers. Application to a microassay of fructose 2,6-bisphosphate. Eur. J. Biochem. 129 191-195 
21 Finegood, D. T., Bergman, R. N. and Vranic, M. (1988) Modeling error and apparent isotope discrimination confound estimation of endogenous glucose production during euglycemic glucose clamps. Diabetes 37, 1025-1034

22 Hue, L. (1987) Gluconeogenesis and its regulation. Diabetes Metab. Rev. 3, 111-126

23 Titanji, V. P., Zetterqvist, 0. and Engström, L. (1976) Regulation in vitro of rat liver pyruvate kinase by phosphorylation-dephosphorylation reactions, catalyzed by cyclicAMP dependent protein kinases and a histone phosphatase. Biochim. Biophys. Acta 422, 98-108

24 Blair, J. B., Cimbala, M. A., Foster, J. L. and Morgan, R. A. (1976) Hepatic pyruvate kinase. Regulation by glucagon, cyclic adenosine $3^{\prime}-5^{\prime}$-monophosphate, and insulin in the perfused rat liver. J. Biol. Chem. 251, 3756-3762

25 Van Schaftingen, E. and Hers, H.-G. (1981) Inhibition of fructose-1,6-bisphosphatase by fructose 2,6-biphosphate. Proc. Natl. Acad. Sci. U.S.A. 78, 2861-2863

26 Pilkis, S. J., El-Maghrabi, M. R., Pilkis, J. and Claus, T. J. (1981) Inhibition of fructose-1,6-bisphosphatase by fructose 2,6-bisphosphate. J. Biol. Chem. 256, 3619-3622

27 Rousseau, G. G. and Hue, L. (1993) Mammalian 6-phosphofructo-2-kinase/fructose2,6-bisphosphatase: a bifunctional enzyme that controls glycolysis. Prog. Nucleic Acid Res. Mol. Biol. 45, 99-127

Received 2 March 2000/17 August 2000; accepted 11 September 2000
28 Kurland, I. J. and Pilkis, S. J. (1995) Covalent control of 6-phosphofructo-2kinase/fructose-2,6-bisphosphatase: insights into autoregulation of a bifunctional enzyme. Protein Sci. 4, 1023-1037

29 Argaud, D., Kirby, T. L., Newgard, C. B. and Lange, A. J. (1997) Stimulation of glucose-6-phosphatase gene expression by glucose and fructose-2,6-bisphosphate. J. Biol. Chem. 272, 12854-12861

30 Paula, F. J. A., Plens, A. E. C. M. and Foss, M. C. (1998) Effects of hypophosphatemia on glucose tolerance and insulin secretion. Horm. Metab. Res. 30 281-284

31 Drezner, M. K. (2000) PHEX gene and hypophosphatemia. Kidney Int. 57, 9-18

32 Wong, C. K., Ho, M. A. and Wagner, G. F. (1998) The co-localization of stanniocalcin protein, mRNA and kidney cell markers in the rat kidney. J. Endocrinol. 158 183-189

33 Moore, E. E., Kuestner, R. E., Conklin, D. C., Whitmore, T. E., Downey, W., Buddle, M. M., Adams, R. L., Bell, L. A., Thompson, D. L., Wolf, A. et al. (1999) Stanniocalcin 2: characterization of the protein and its localization to human pancreatic alpha cells. Horm. Metab. Res. 31, 406-414

34 Xie, W., Tran, T. L., Finegood, D. T. and van de Werve, G. (2000) Am. Diabetes Assoc. 60th Annu. Sci. Sess., San Antonio, TX, U.S.A., 10-13 June 2000 